\title{
EI nihilismo en Crimen y castigo de Dostoievski
}

\author{
Dostoievsky's nihilism in Crime and punishment
}

'Germán Rivas Truebas

Dostoievski es el único psicólogo, por cierto, del cual se podía
aprender algo, es uno de los accidentes más felices de mi vida,
más incluso que el descubrimiento de Stendhal. Friedrich Nietzsche.

El verdadero profeta del siglo diecinueve fue Dostoievski, no Karl Marx.

Albert Camus.

Aprendí más de Dostoievski que de cualquier otro pensador científico.

Albert Einstein.

\section{RESUMEN}

Este trabajo representa un recorrido por la principal novela del escritor ruso Fiódor Dostoievski. Tuvo como objetivo demostrar que el libro Crimen y castigo contiene aspectos nihilistas. La metodología utilizada fue el empírico-analítico y la técnica, el análisis de contenido. Se concluyó que el nihilismo en el libro Crimeny Castigo se ve representado en el artículo Acerca del delito y los soliloquios, desarrollado por Rodión Raskólnikov.

Palabras clave: Nihilismo, crimen, castigo, conciencia, remordimiento.

\section{ABSTRACT}

This work represents a tour of the main novel by Russian writer Fyodor Dostoyevsky. It was intended to show that the book Crime and Punishment contains nihilistic aspects. The methodology used was the empirical-analytical and the technique, the analysis of content. It was concluded that nihilism in the book Crime and Punishment is represented in the article About Crime and Soliloquies, developed by Rodion Raskolnikov.

Keywords: Nihilism, crime, punishment, conscience, remorse.

\section{INTRODUCCIÓN}

Fiódor Mijáilovich Dostoyevski es un escritor ruso que ha influenciado en un sin número de pensadores a nivel mundial, decimos pensadores porque su trascendencia no se limita a la literatura o a la filología, su prosa y específicamente la polifonía presente en sus novelas es simplemente isoberbio, excelso!, llegando a ser admirado y estudiado desde diferentes disciplinas, tales como la psicología, filosofía e incluso, la psiquiatría. El éxito conseguido fue algo que no consideraba el escritor ruso, prueba de ello es la confesión que hizo a su sobrina, veamos: "yo estoy seguro de que si dispusiese para escribir una novela, de dos a tres años "lujo que pueden permitirse Turguéniev, Gonchárov y Tolstoi" me saldría una obra de la que se hablaría aún pasado un siglo" (Dostoievski, 2004, p. 57).

${ }^{1}$ Universidad Nacional Jorge Basadre Grohmann. E-mail: german.rivas.truebas@gmail.com

Presentado: 07/07/2020, Aprobado: 05/06/2020 
La literatura de Dostoievski trasciende en el tiempo porque podemos vislumbrar puntos de encuentro con el hombre actual. Así es porque Dostoievski defendió sus ideales, los que creía correctos y por ellos tuvo que pasar mucho tiempo privado de su libertad, este acontecimiento cambió su pensar psicológico. Se constituye así en el punto de quiebre que marcaría un antes y un después no solo en su vida, también en su producción literaria. Este cambio lo podemos vislumbrar en su novela Crimen y castigo y su alter ego podría ser Raskólnikov, claro está, cada uno con sus propios matices. Pero para comprender el libro primero debemos caracterizar lo que es el nihilismo.

\section{Genealogía del nihilismo}

El término nihilismo tiene diferentes conceptos como diferentes significados, varía según el lugar y el tiempo en el que se lo estudie, también los criterios ideológicos como filosóficos del investigador. Veamos, hace algunos años la tesis más aceptada por la comunidad académica era que el término se había originado en Rusia en el año 1862, esto debido a la producción literaria del escritor Turgenev, al respecto G. Benn (1999), menciona:

(...) si deseamos constatar en qué lugar y en qué momento de la historia del espíritu europeo se presentó por vez primera este concepto fatal como palabra y como vivencia espiritual, tendremos que volver nuestra mirada, como es sabido, hacia Rusia. Su fecha de nacimiento fue marzo de 1862, el mes en que se publicó la novela Padres e hijos de Ivan Turgenev. Los historiadores rusos no pueden remontarse más atrás en su investigación sobre los antecedentes de este concepto. Sin embargo, su héroe. Basárov, es ya todo un nihilista y Turgenev lo presenta con este nombre. (pág. 106)

Precisamente en la novela de Turgenev surge un diálogo muy esclarecedor respecto a nuestra investigación, veamos:

— ¿Que qué es Basarov? — sonrió Arkadii - ¿Es qué quiere usted, tío, que yo le diga lo que es?

- Hazme el favor, sobrino.

- Pues es nihilista.

— ¿Cómo? - preguntó Nikolai Petrovich; pero Pavel Petrovich levantó en el aire el cuchillo untado de manteca en su afilada punta, y quedóse inmóvil.

— Es nihilista -repitió Arkadii. (pág. 17)

En esta conversación los personajes del libro intentan significar la posición política y filosófica de Básarov; en ella, Arkadii es contundente respecto al término en cuestión y continúa el diálogo, veamos:

— Nihilista — recalcó Nikolai Petrovich - Eso viene del latín nihil (nada), según creo recordar; probablemente, esa palabra designa... que no cree en nada.

— Di más bien que nada respeta encareció Pavel Petrovich; y volvió a emprenderla con su mantequilla -

- Que a todo aplica su punto de vista crítico - observó Arkadii- .

— ¿Y no viene a ser todo uno? -Preguntó Pavel Petrovich-.

- No; no es todo lo mismo. El nihilista es un hombre que no acata ninguna autoridad, que no tiene fe en ningún principio ni les guarda respeto de ninguna clase, ni se deja influir por ellos. (pág. 30)

De la lectura se desprende que el término nihilista era dado a la persona libertaria. Sería, en tal caso, un protoanarquista.

Siguiendo con Benn (1999), respecto a la novela Padres e hijos y el personaje principal que en ella narra, menciona que:

El nihilismo de Basárov no era, a decir verdad, un nihilismo en su forma absoluta, no era un negativismo total, sino una fe fanática en el progreso, un positivismo radical inspirado en las ciencias de la naturaleza y en la sociología. Representa, por primera vez en la historia de la literatura europea, el mecanicista consciente de su victoria, el materialista vehemente... Un químico competente, se nos dice, es veinte veces más valioso que el mejor poeta. Prefiero un trozo de queso al mejor Pushkin. Pero ¿no estima usted en nada el arte? Claro que sí: el arte sirve para hacer dinero y curar hemorroides. Cualquier 
zapatero es superior a Goethe y Shakespeare. Georges Sand es una mujer rezagada. Pues no era una entendida en embriología. Y junto a estas verdades entra en escena... el ambiente de lupanar... el culto del atleta, el himno al hombre mediocre, la crítica social pueril. Se deben eliminar los tribunales, suprimir la educación; deben prohibirse las lenguas antiguas por falta de genialidad; ya basta con los impulsos: el hombre debe ser sucio, debe intercambiar las mujeres y dejar que otros las mantengan; hay que beber, pues beber es más barato que comer, y además hay que apestar a bebida... (pág. 106)

Lo anterior denota una interpretación sui géneris de Benn (1999) respecto al personaje del libro de Turgenev; sin embargo, por esos años el término nihilismo era más que una posición política frente al zarismo ruso, se concebía como una ideología libertaria y todavía en construcción por los intelectuales y jóvenes de tendencia radical. Uno de los biógrafos más lúcidos de Dostoievski lo caracteriza como un "utilitarismo inglés, socialismo utópico francés, ateísmo feurbachiano y burdo materialismo y determinismo mecánico" (Frank, 1997, p. 23). Esta ideología, aún en construcción, sedujo los primeros años de la juventud de Dostoievski. Sin embargo, ocurre un acontecimiento en la vida de nuestro escritor que sería el punto de quiebre que cambiaría toda su filosofía y que más adelante plasmaría en sus libros, esto es: su reclusión en Siberia. Este hecho cambia todo su ser, la convivencia con reclusos de las más calamitosas realidades sociales tocan su alma, recordemos que Dostoievski era un tipo educado e intelectual, y más adelante profesa con pasión un catolicismo ortodoxo, credo que plasmaría en sus libros, verbigracia. La redención de Raskólnikov en Crimen $y$ castigo con valores como el amor, la compasión y el sufrimiento.

Regresando al libro que cambió la psique de miles de jóvenes rusos, nos referimos a Padres e hijos de Turgenev, el personaje principal llamado Basárov es un personaje que no cree en nada, rompe todo el orden establecido, no solo en el aspecto político, también en la ciencia, a la que considera como falaz. Respecto a su particular forma de nihilismo, veamos en la propia novela de Turgenev (1987):

- Nosotros actuamos en virtud de aquello que considerarnos útil- replicó

\section{Basárov-.}

- Y en el tiempo actual lo más útil es la negación. Por eso nosotros negamos.

- ¿Todo?

- Todo.

— ¿Cómo? No sólo el arte, la poesía, sino... da miedo decirlo...

— Todo -repitió Basárov con indescriptible serenidad - .

- Pavel Petrovich quedose confuso. No se esperaba aquello; pero Arkadii hasta se puso encarnado de puro placer.

- Sin embargo..., permita usted... -balbució Nikolai Petrovich -

- Ustedes lo niegan todo, o dicho con más exactitud, lo destruyen todo... Pero luego es menester construir.

- Eso ya no es cosa nuestra... Lo primero de todo es descombrar... (pág. 50)

Como vemos, la novela de Turgenev rompía los esquemas de cualquier sociedad y con especial significación en el pueblo ruso, no solo por el mensaje eufórico de Básarov, también por su cosmovisión empirista e individualista, se erige así como un referente de los jóvenes que veían en él un modelo a seguir para luchar contra el régimen imperante y todo lo conocido. Es un nihilismo propio de aquellos años.

Líneas arriba decíamos que por un buen tiempo se aceptó que el término nihilista encontró la luz en el año 1862. Sin embargo, investigaciones más recientes en el campo de la filología refieren que el término en verdad habría nacido mucho antes, esto es en 1799 y que el primero en acuñar la palabra fue Jacobi, pero él no sería el único, también varios autores alemanes entre los que destacan Immermann, Gorres, Meinhold y Auerbach, entre otros, respecto a Jacobi, veamos lo que dice Max Maureira (2010):

En la carta que, en 1799, Jacobi le envió a Fichte, la más larga e importante de cuantas le remitió, aparece ocupando un lugar central la cuestión de la nada. Allí Jacobi refiere a la filosofía fichteana como nihilismo, siendo ésta acaso la primera vez que Jacobi utiliza este término. La filosofía de Fichte representa, de acuerdo con Jacobi, una filosofía de la nada. Jacobi no sólo está convencido de que en la filosofía fichteana se oculta una suerte de 
nihilismo, sino que advierte además las consecuencias que se siguen de ello. (pág. 2)

En la carta que se menciona se discute el espectro de la nada, además de la realidad ideal y empírica, sigamos en Maureira (2010):

Pero, ciertamente también, y sobre todo, el acontecimiento Jacobi frente a Fichte es importante por lo que el problema del nihilismo ha significado y significa aún hoy para la filosofía, ya que desde entonces no ha desaparecido de la discusión filosófica. Así, pues, cabe preguntarnos aquí: ¿a qué se refiere Jacobi exactamente con la nada?, ¿por qué, a juicio suyo, se deja caracterizar la filosofía de Fichte como nihilismo? (pág. 1)

Bien, de lo anterior debemos mencionar que en Jacobi se constituye al nihilismo desde una discusión filosófica, cobra especial relevancia el problema de la materia, mientras que en Rusia y específicamente entre los autores rusos, la palabra nihilismo era abordada no en la filosofía, ergo lo hacían en la literatura y su objetivo era para narrar el contexto social, político y económico de su país, claro está que más adelante, esto es, siglo XIX el nihilismo sería estudiada por completo a partir de la filosofía por pensadores como Kant, Nietzsche, Heidegger, entre otros, pero también, en la literatura como Arthur Schopenhauer, Camus y demás escritores.

\section{EI nihilismo en Nietzsche}

Nuestra investigación intenta demostrar los presupuestos nihilistas en la retórica de Raskólnikov, personaje principal de la novela Crimen y castigo, no obstante, es menester caracterizar los tipos de nihilismo que existen, para efectos de nuestra investigación seguiremos el nihilismo en el pensamiento de Nietzsche porque de acuerdo a la literatura académica, consideramos que es el nihilismo que más se ajusta al que es mostrado por Raskólnikov.

Respecto a Nietzsche, debemos mencionar que es un filósofo bastante sui géneris y, como todo genio que se adelantó a sus coetáneos, fue terriblemente incomprendido, ya que rompió esquemas antes insospechados que podrían ser acaso cuestionados, y como dice Eugen Fink (1981):

(...) la grandeza de Nietzsche como pensador consiste en que camina hacia lo intransitado, en que se sale de una senda que durante muchos siglos ha guiado al pensamiento de occidente (...) Nietzsche experimenta que la necesidad de la época es ser un tiempo final. (pág. 180)

Debemos ser categóricos en mencionar que Nietzsche jamás escribió algún libro que llevase como título "el nihilismo" o algo que se le parezca. No obstante, en nuestra investigación intentaremos acercarnos a su pensamiento. Somos sinceros y cautos en utilizar la palabra "intentaremos", pues el pensamiento de Nietzsche es bastante complejo, no porque escriba en difícil, ergo sus libros tocan capas muy delgadas en la psicología y filosofía del hombre. $\mathrm{Su}$ profundidad es tan abrumadora que, en cada pensamiento expresado en sus libros, hace que el lector debata mucho más que su fe, su ciencia y hasta su propia vida. Hay tantas interpretaciones del pensador alemán como tantos rostros de nietzsches, verbigracia, está el Nietzsche ateo, el Nietzsche nacional socialista, también el Nietzsche nazi, el Nietzsche anarquista, entre muchos otros. No obstante, debemos confesar que uno de nuestros preferidos es el Nietzsche anarquista, sin embargo, nosotros trataremos de estudiarlo lejos de las pasiones humanas, lejos de las ideologías, para ello trataremos de mostrar su propia voz.

Veamos, decíamos que Nietzsche no escribió ningún libro con el nombre de nihilismo; no obstante, todo su pensamiento radica en el nihilismo y para entenderlo hay que estudiar cada uno de sus libros y unir las ideas que en ellas están presentes. Por tanto, el nihilismo de Nietzsche es la crítica a la moral judeocristiana, a sus valores, a la metafísica platónica, esto es, el mundo sensible y el mundo suprasensible. Nietzsche rechaza los valores platónicos que se hayan en el mundo suprasensible, estos son: verdad, bien, bello, por ende realiza una transvaloración de esos valores, fundamenta así un tipo ideal de hombre, es decir, para Nietzsche debe existir un tipo de hombre al que da el nombre de Übermensch que significa suprahombre o superhombre con valores determinados y basados en sus propios principios, claro está totalmente alejados del mundo suprasensible de Platón. Este hombre, al que da el nombre de Übermensch, tiene similitudes con el personaje de Raskólnikov, la semejanza está en que ambos se muestran con mayor capacidad y voluntad que el resto, ambos se sienten integrantes de una casta especial, asimismo ambos rechazan los valores morales, verbigracia, el principio de no matar. 
De acuerdo a Nietzsche (1981), respecto al nihilismo se pregunta: ¿qué significa el nihilismo?: Que los valores supremos pierden validez. Falta la meta; falta la respuesta al por qué (p. 35). Preguntamos ¿De qué valores supremos habla Nietzsche? Respondemos, se refiere a los valores supremos por los cuales la religión católica se fundó, Nietzsche ante todo es anticristiano, rechaza los valores como el amor al prójimo, la compasión, el ascetismo, a los que designa como valores blandos o de personas débiles, defiende así los valores fuertes, esto es, la dureza, los valores de la guerra, esta idea última la encontramos presente en El Anticristo (1973), lectura dura y contundente del pensamiento nietzscheano. El nihilismo de Nietzsche rechaza los valores platónicos y propone por tanto nuevos valores en la genealogía de la moral.

Se puede decir que el nihilismo en Nietzsche distingue dos estadios en la psicología del hombre, esto son, el nihilismo pasivo y nihilismo activo, respecto al primer estadio se representa en la sentencia de "Dios ha muerto", veamos:

¿A dónde ha ido Dios?, gritó, ¡yo os lo voy a decir! ¡Nosotros lo hemos matado-vosotros y yo!- ¡Todos nosotros somos sus asesinos! ¿Pero cómo hemos hecho esto? ¿Cómo fuimos capaces de beber el mar? ¿Quién nos dio la esponja para borrar todo el horizonte? ¿Qué hicimos cuando desencadenamos esta tierra de su sol? ¿Hacia dónde se mueve ahora? ¿Hacia dónde nos movemos nosotros? ¿Lejos de todos los soles? ¿No caemos continuamente? ¿Y hacia atrás, hacia los lados, hacia adelante, hacia todos los lados? ¿Hay aún un arriba y un abajo? ¿No erramos como a través de una nada infinita? ¿No nos sofoca el espacio vacío? ¿No se ha vuelto todo más frío? ¿No llega continuamente la noche y más noche? ¿No habrán de ser encendidas lámparas a mediodía? ¿No escuchamos aún nada del ruido de los sepultureros que entierran a Dios? ¿No olemos aún nada de la descomposición divina? -también los dioses se descomponen-. ¡Dios ha muerto! ¡Dios permanece muerto! ¡Y nosotros lo hemos matado! (Nietzsche, 1992, pág. 115)

La cita anterior se encuentra en la Gaya ciencia (1992), la edición que estamos usando es la realizada por José Jara y la elegimos por su estilo característico. Bien, respecto a lo citado debemos mencionar que fue pronunciado por un hombre muy en particular que aparece en el libro, al respecto es menester detenernos un momento para caracterizar a ese personaje, pues no todas las investigaciones y no todos los eruditos en el pensamiento nietzscheano coinciden. La disputa está en la traducción, en el texto original aparece la palabra toll. Algunos la han traducido como loco o frenético; sin embargo, investigaciones recientes de Sánchez Meca (2015) la concibe como "genial", que como sustantivo se entiende como persona genial o persona de conocimientos geniales. Regresando a la cita, Depaz Toledo (2019) realiza una interpretación muy interesante, así:

Nietzsche presenta a un personaje que anuncia por las calles que Dios ha muerto. Algunos, que se burlan de él, parecen decir: ¿cómo puede morir lo que nunca ha existido? Es obvio que se trata de ateos, sujetos que, como tipo, son característicamente modernos. Podríamos preguntarnos, por tanto, qué sentido tiene predicar a los ateos que Dios ha muerto y que, encima, ellos no se han dado cuenta. Pues bien, sin reconocerlo, el ateo sería un típico creyente, ya que cree saber la Verdad. Con ello ha reemplazado al Dios tradicional por uno nuevo. Tiene su Dios, su Absoluto; se llama Ideología. Lo que Nietzsche postula es un ateísmo más radical. No dice que Dios no exista (eso sería afirmar una Verdad, implicaría saber el fondo último de todas las cosas), lo que dice es que Dios ha muerto; que ya no hay Verdad en qué creer; que todo son ilusiones y que lo más grave es que aún no nos damos cuenta de todo lo que eso implica. (pág. 19)

Al respecto, debemos coincidir con Depaz Toledo, pues la modernidad, el positivismo, la cultura del envase, la mecanización del trabajo, la videocracia, los programas de farándula y demás males de nuestra sociedad han producido diversos efectos, uno de ellos es la secularización religiosa, la desacralización del mundo y la desvaloración de la vida, entre otros. Siguiendo con Depaz Toledo (2012), respecto a la cultura moderna menciona que "no deja lugar para el misterio, la ilusión; lo vuelve todo calculable, manipulable, dominable, extinguiendo radicalmente la fe en que pueda haber algo así como un sentido del mundo" (p. 19). Esto 
último es importantísimo pues al estudiar con detenimiento el pensamiento de Nietzsche podemos decir que su objetivo es exhortar al hombre a que se libere de todas las ataduras y se entregue al misterio, a lo desconocido, que viva según sus propios sentido, sería por tanto, su visión del Dionisios, figura sumamente interesante que construye Nietzsche, pero esto último será abordado en futuros trabajos.

Respecto al nihilismo pasivo, debemos precisar que es el estado de la muerte de Dios, veamos, la cultura de occidente ha mencionado que los valores morales se sostienen en algo trascendente, cuasi metafísico y a consecuencia de ello la vida tiene verdadero sentido y por ende las sociedades y, dentro de ella, las relaciones humanas, se desarrollan en comunión, dicho de otra forma, como los valores morales dictan las relaciones humanas y la moral como producto de la cultura han posibilitado una economía en movimiento y demás actividades sociales, sin embargo, y, aquí viene lo sustancial de la frase nietzscheana, con la muerte de Dios la vida carece de sentido, es insostenible, vacía, hueca y esto produce la crisis total, veamos en el propio Nietzsche (1992):

¡Dios ha muerto! ¡Dios permanece muerto! ¡Y nosotros lo hemos matado! ¿Cómo nos consolamos los asesinos de todos los asesinos? Lo más sagrado y lo más poderoso que hasta ahora poseía el mundo, sangra bajo nuestros cuchillos - ¿quién nos lavará esta sangre? ¿Con qué agua podremos limpiarnos?-(pág. 115)

Por tanto, el nihilista pasivo es un estado psicológico en el que se tiene una existencia pesimista porque niega la vida y toda esperanza. Como Dios está muerto todo lo que queda es el hombre con sus limitaciones y frustraciones. Pero en el pensamiento de Nietzsche no se limita a ello, trasciende, veamos:

¿Qué fiestas expiatorias, qué juegos sagrados tendremos que inventar? ¿No es la grandeza de este hecho demasiado grande para nosotros? ¿No hemos de convertirnos nosotros mismos en dioses, sólo para aparecer dignos ante ellos? ¡Nunca hubo un hecho más grande $-\mathrm{y}$ quienquiera nazca después de nosotros, pertenece por la voluntad de este hecho a una historia más alta que todas las historias habidas hasta ahora! (Nietzsche, 1992, pág. 115)
La muerte de Dios no hay que considerarla en su sentido literal, pues es más una metáfora, veamos, la muerte de Dios no es la ventana, ergo es la puerta principal al nihilismo, esto es, a la desvalorización de la vida de occidente, a la desacralización. Dios ha muerto significa, por tanto, que todos los valores platónicos (del mundo suprasensible), además de todos los valores que tienen que ver con el Dios judeocristiano han desaparecido. Este pensamiento es magistralmente explicado en la Genealogía de la moral (1972) de Nietzsche. Donde, por razones de extensión y objetivos temáticos, solo diremos que el pensador alemán sostiene que el bien y el mal han sido designados por el poder, es decir, es el poder quien crea la verdad, la cultura griega ha dictado lo que es bueno y lo que es malo y las civilizaciones posteriores han seguido ese talante. $\mathrm{Al}$ respecto y sin ánimos de adelantar el análisis que haremos de Raskólnikov, debemos decir que el personaje principal del libro Crimen y castigo a prima facie es todo un nihilista, pues en los soliloquios que sostiene antes de cometer su crimen no le preocupa el bien o el mal, al contrario está totalmente de acuerdo en asesinar a su presa elegida porque lo guía una idea más fuerte, es decir, que es un superhombre, pero esto lo analizaremos más adelante

Ahora bien, debemos ser categóricos en mencionar que la muerte de Dios, a entender de Nietzsche, no trajo consigo la desacralización del mundo, ergo es precisamente la afirmación de aquél Dios. En Asi habló Zaratustra (1985) se hace referencia no a un Dios, sino a dioses:

Los viejos dioses hace ya mucho tiempo, en efecto, que se acabaron: iy en verdad, tuvieron un buen y alegre final de dioses! (...) encontraron su propia muerte, ;riéndose! Esto ocurrió cuando la palabra más atea de todas fue pronunciada por un dios mismo; la palabra: ¡Existe un único dios! ¡No tendrás otros dioses junto a mí! Un viejo dios huraño, un dios celoso se sobrepasó de ese modo. Y todos los dioses rieron entonces, se bambolearon en sus asientos y gritaron: ¿No consiste la divinidad precisamente en que existan dioses, pero no dios? El que tenga oídos para oír, oiga (pág. 256).

Al respecto Sánchez Meca (2015) y Depaz Toledo (2012) realizan una interpretación muy interesante que podemos parafrasear en lo siguiente: con lo dicho en Así habló Zaratustra, Nietzsche propone la 
idea animista, es decir que todo en el mundo está animado, esto es: con vida y por tanto todo merece valor, no hay Verdad absoluta, no más ideologías, sería la resultante del nihilismo positivo, no negativo.

La transvaloración de los valores del que habla Nietzsche es la etapa del nihilismo pasivo o negativo como otros investigadores la han llamado, sin embargo, Nietzsche trasciende, es decir va mucho más allá de la crítica a los valores morales de occidente, no se queda en un nihilismo individual y ello se ve magistralmente analizado en Más allá del bien y del mal (1972), en efecto:

También aquel cuerpo dentro del cual, como hemos supuesto antes, trátense los individuos como iguales -esto sucede en toda aristocracia sana-debe realizar, al enfrentarse a otros cuerpos, todo eso de lo cual se abstienen entre sí los individuos que están dentro de él, en el caso de que sea un cuerpo vivo y no un cuerpo moribundo: tendrá que ser la encargada voluntad de poder, querrá crecer, extenderse, atraer a sí, obtener preponderancia, no partiendo de una ética o falta de ética cualquiera, sino porque vive, y la vida es cabalmente, voluntad de poder. (pág. 235)

Esta cita es fundamental para comprender la voluntad de poder en Nietzsche. Al respecto, Feinmann (2016), en Filosofía aqui y ahora, menciona que los dos ejes dinámicos de la voluntad de poder son conservación y aumento, aquí Feinmann es contundente en su interpretación acerca la voluntad de poder de Nietzsche al decir que es un ir más allá constantemente, esto sería el expansionismo geopolítico de un Estado poderoso, claro, porque si la voluntad de poder es conservar el territorio conquistado, el aumento sería conseguir nuevos territorios, líneas arriba decíamos que hay muchas interpretaciones respecto al pensamiento nietzscheano, uno de ellos es el que fue tomado por el nacional socialismo alemán y quien personifica esta idea es Hitler en su afán de expansionismo de su idea de espacio vital, al respecto y a entendimiento de Feinmann, Hitler sería la personificación del superhombre nietzcheano. Recordemos que Adolf Hitler no tenía reparos en ordenar asesinar, estaba lejos de los preceptos cristianos y en tanto lejos del mundo suprasensible de Platón, esta última idea la podemos unir con el razonamiento del joven
Raskólnikov al pensar que él mismo podría ser un hombre napoleónico, es decir, capaz de asesinar sin que su acto traiga consigo consecuencias del tipo moral y demás, pero como dijimos el análisis del nihilismo en Raskólnikov lo veremos en el siguiente capítulo.

A entender de Nietzsche, el mundo sigue siendo uno. No obstante; necesita, requiere de una instancia que genere nuevos valores, pero el agente instauradorcreativo no es una figura divina o absoluta, ergo es la propia humanidad, dentro de él los filósofos o el aristócrata espiritual, recordemos que Nietzsche era un fiel admirador de la tradición griega y, por tanto, exaltaba la capacidad el filósofo, esto último puede ser estudiado en lo que se ha llamado como Fragmentos póstumos (2008), que es un conjunto de pensamientos que Nietzsche escribió los últimos años de su vida justo antes de ser internado en las clínicas para tratar su estado de locura.

Respecto al nihilismo, cual profeta, Nietzsche (2008) vislumbra lo siguiente:

Yo describo lo que viene: el ascenso del nihilismo. Puedo describirlo porque aquí se produce algo necesario - de ello hay signos por todas partes, solo faltan los ojos que los perciban-. Yo elogio, no critico aquí, que venga: creo que habrá una de las crisis más grandes, un instante de autorreflexión sumamente profunda del ser humano: si éste se repondrá de ello, si el ser humano dominará esta crisis, eso es una cuestión que depende de su fuerza: es posible que lo haga...

el ser humano moderno cree a modo de ensayo ora en este valor, ora en ése, y luego deja que esos valores vayan cayéndose: el círculo de los valores a los que ha sobrevivido y ha dejado que se cayeran va llenándose sin cesar; el vacío y la pobreza de valores alcanzan a sentirse cada vez más; el movimiento es imparable-aunque se ha intentado demorarlo con gran estilo-.

Finalmente, él se atreve a una crítica de los valores en general; les reconoce su procedencia; llega a conocer lo suficiente para no creer ya en ningún valor; he aquí el pathos, el nuevo estremecimiento... Esto que cuento es la historia de los próximos dos siglos... (pág. 400, 401) 
En suma, el nihilismo en Nietzsche es un proceso. Primero, es la desvalorización de los valores supremos (moral judeocristiana) que ha nihilizado todo, así se constituye la muerte de Dios, donde se niega todo, es el constituyente del estado de la nada, donde se expresa que el platonismo convirtió a la nada todo, y como no hay nada absoluto deviene el nihilismo clásico o consumado que instaura valores. Dicho de otra forma, crea nuevos valores y se constituye el superhombre o el Übermensch nietzscheano libre de las ataduras del mundo suprasensible y construye su ideario teniendo como fundamento la vida, así el Übermensch es capaz de hacer su talante, esto es: la voluntad de poder con sus dos pilares, ergo conservación y aumento, y, en seguida, el Dionisios del que hablaremos en próximos trabajos.

\section{La representación del nihilismo}

\section{El nihilismo en la actualidad}

Al estudiar la literatura de Dostoievski y, en forma particular, el nihilismo; el lector se ve acompañado de temas sustanciales de la vida humana, es por eso que muchos investigadores desde diferentes disciplinas la han abordado. Es así que se han organizado simposios, congresos y hasta sociedades literarias en todo el mundo, en este apartado presentaremos algunos estudios recientes.

Por ejemplo, Juan Sánchez Alva (2014) presentó la tesis Nietzsche y Dostoievski ante el nihilismo, en la Universidad Nacional Autónoma de México. Esta investigación se planteó esclarecer el término nihilismo desde un enfoque histórico-social, soslaya el enfoque semántico. Por el contrario, hace énfasis en estudiar la palabra en el contexto ruso del siglo XIX, época en la que vivió Nietzsche y Dostoievski. Para lograrlo, realiza un estudio metodológico comparado buscando diferencias y similitudes entre ambos autores frente al nihilismo. Las conclusiones a las que llegó Sánchez Alva son que para Nietzsche, el nihilismo cuestiona la moral judeocristiana. Por tanto, busca una nueva ética moral, mientras que en Dostoievski propone una acción espiritual a nivel social y comunitario.

Por otro lado, Benamí Barros García (2011), presentó la tesis doctoral Análisis y visualización del discurso en la obra Crimen y castigo de F. M. Dostoievski, en la Universidad de Granada, Departamento de Filología Griega y Eslava. Esta investigación persiguió analizar el discurso en la obra de Dostoievski y para ello se vale de la lingüística. Para explicar la retórica de Dostoievski, el autor de la tesis singulariza "entre intención e intencionalidad, lector modelo y receptor, polivalencia y ambigüedad, intencionalidad y recepción" (p. 14) en el discurso dostoievskiano. Las conclusiones a las que llegó son: "los mecanismos empleados por el autor de manera recurrente para discursivizar las ideas que quiere presentar remiten a la distribución de la información y a la dotación de potencial retórico a cada uno de los eventos textuales que conforman la red de sentido"(p.342).

También, se tiene que Joao Vilas Boas (2019), investigador de la Universidad Federal de Paraná, Brasil, quien escribió el libro Nihilismo e grande política em Nietzsche a aurora da superacao humana a partir da morte de deus, uno de los paradigmas que sigue la temática del libro es saber cuál sería la posición política de Nietzsche y caracterizar la gran política (moral) -a partir de la muerte de Dios- para la humanidad. Una de las conclusiones a las que llegó el autor del libro es que la superación del nihilismo (la gran política) no tiene alcance universal, es decir, solo es para un cierto tipo de hombres, esto es: para aquellos que superen toda visión idealizada-religiosa, que lejos de sucumbir ante la depresión y ausencia de fundamentos "continuam a viver e a afirmar a vida, criando novas verdades, novas perspectivas e novos valores" (p. 154). En ese sentido, sería "uma política para homens de exceção"(p. 154).

Asimismo, se tiene que L. Sáez, J. de la Higuera y J. F. Zúñiga (2007), escribieron el libro Pensar la nada, ensayos sobre filosofía y nihilismo, en este libro se presentan un conjunto de ensayos cuyo paradigma central es filosofar respecto al doble falaz que encierra el término nihilismo. "El tema central, sin embargo, consigue un desarrollo solo bajo la hipótesis de que el nihilismo posee una génesis y un desarrollo en la historia entera de occidente y que despierta, al mismo tiempo, una proyección de futuro" (p. 16).

\section{Raskólnikov, ¿Elsuperhombre?}

La obra de la tristeza sin salida, como diría Bravo (1987, p. 87), respecto a Crimen y castigo, es una joya de la literatura, no solo rusa, también universal, 
en cada hoja el lector siente que se va una parte de su alma, en otras le trae a colación reminiscencias de su adolescencia, de un dolor apasionado. Crimen y castigo es, como diría el gran Kafka en la carta escrita a su amigo Pollak, uno de esos libros que " $(. .$.$) te hieren o apuñalan... es como un exilio a un$ bosque apartado de todos, como un suicidio. (...) es el hacha para el mar congelado en nosotros (1904, p. 02)", es un libro que marca a sus lectores, una vez leído el libro no se puede ser la misma persona.

Para contextualizar la temática del libro debemos mencionar que el personaje principal es Rodión Raskólnikov, quien es un ex estudiante de la carrera de derecho, además integrante de una familia pobre, razón por la que se ve obligado a abandonar sus estudios. Este hecho es clave para la construcción de la psicología del joven pues, al dejar la universidad, el único espacio físico en el que desarrolla su vida es en un viejo cuarto. Aislado del mundo, no solo se ve limitado por la compañía humana, también pasa hambre, frío y demás situaciones límite, verbigracia, no tiene dinero para pagar la renta, entre otros. El conflicto del libro está en que el joven Raskólnikov quiere probarse así mismo si es un superhombre. Para lograrlo, elige asesinar a una prestamista, este hecho ocasionará un cisma en su psicología que se evidenciará en sus soliloquios que más adelante analizaremos.

Una de las pocas personas con las que se relaciona es Sonia Marmeládov, joven que se prostituye para llevar dinero a su familia. Esta muchacha se convertiría como un bálsamo para su lúgubre vida, a ella le confiesa: "¿Y sabías, Sonia, que los techos bajos y las habitaciones estrechas estrechan el alma y la mente? ¡Oh, cómo odiaba yo ese cuartucho! Pero de todos modos no quería salir de él. ¡Adrede no quería!" (Dostoievski, 1982, p. 514)

La literatura de Dostoievski puede entenderse desde diferentes aristas, una de ellas -acaso la más importante- es que expone a través de la historia de los personajes de sus libros la tesis que la modernidad es una época en la que el hombre desarraiga la fe divina, el racionalismo que enjuicia la fe no es compatible con la religión, ello ocasiono que el hombre se pusiera al nivel de Dios, sería una suerte de deificación del hombre, por tanto la secularización del cristianismo, estas ideas se ven reflejadas en Los demonios, Los hermanos Karamazov y claro en Crimen y castigo.
La retórica que expresa Raskólnikov antes de asesinar a usurera Aliona Ivánovna es la exposición del nihilismo nietzscheano (el superhombre cuasi Übermensch). Claro está que Dostoievski no había leído a Nietzsche; no obstante, en lo que respecta al nihilismo que estamos estudiando sería su equivalencia. Para evidenciar lo anterior, nos remitiremos al propio libro que estamos estudiando. Veamos, durante mucho tiempo hay una idea que deambula por la mente del joven Raskólnikov, es como un sueño que precipita todo su ser, que no lo deja en paz y con el paso del tiempo se apodera de él, esto es: que existe dos tipos de hombres: el hombre normal sujeto a la moral oficial y el hombre napoleónico capaz de hacer los más descabellados actos sin perjuicio de ser cuestionado por ellos. Entonces, para ese tipo de hombres no existe moral oficial, sería la resultante del nihilismo, el de entera libertad, creadores de la moral, provistos de la capacidad de estar por encima de las convenciones morales que acepta la sociedad (moral judeocristiana). Además que este tipo de hombres, a entender de Raskólnikov, son excelsos, integrantes de una casta privilegiada. Son seres extraordinarios provistos de una inteligencia singular, el propio Raskólnikov reflexiona:

Y ahora sé que quien es dueño de su voluntad y posee una inteligencia poderosa consigue fácilmente imponerse a los demás hombres; que el más osado es el que más razón tiene a los ojos ajenos; que quien desafía a los hombres y los desprecia conquista su respeto y llega a ser su legislador. (Dostoievski, 1982, pág. 529)

Así, Raskólnikov se siente integrante de ese linaje. Este joven es todo un intelectual que no tiene miedo de defender sus ideas, precisamente en un pasaje del libro desarrolla una tertulia con Porfirio Petrovich, personaje que cumple el rol de juez de instrucción, así Petrovich manifiesta:

No, no, no se trata de eso -respondió Porfirio-. En el artículo en cuestión los hombres se dividen en ordinarios y extraordinarios. Los primeros deben vivir la obediencia y no tienen derecho a violar la ley, teniendo en cuenta que son hombres ordinarios; los segundos tienen derecho a cometer todos los crímenes y a prescindir todas las leyes, por aquello de que son hombres extraordinarios. Creo que es eso lo que usted dice, sino me engaño. (Dostoievski, 1982, pág. 457) 
Lo anterior es lo que dice Petrovich respecto al artículo escrito por Raskólnikov, donde este expone lo particular de su nihilismo. En este artículo se ve reflejado el nihilismo pasivo que analizamos en la sección anterior, esto es: la crítica a la moral judeocristiana, a sus valores, entre otros.

La razón que define el crimen de Raskólnikov (asesinar a un prestamista), es probarse a sí mismo que es un superhombre, que puede transgredir todas las convenciones morales, Nietzsche lo llamaría el Übermensch:

yo necesitaba saber entonces, y saberlo cuanto antes, si yo era también un piojo, como todos, o un hombre. ¿Estaba facultado para transgredir la ley o no lo estaba? ¿Era osado a traspasar los límites y aprehender o no? ¿Era yo una criatura que tiembla, o tenía derecho? (Dostoievski, 1982, pág. 309)

La idea de que existen los superhombres no solo la medita en sus soliloquios, también lo hace al público, el medio elegido es una revista en la que escribe el artículo antes mencionado:

la persona extraordinaria tiene derecho a permitirse en su conciencia la infracción de ciertos obstáculos y solo cuando lo exige la realización de su idea... idea de la que en algún caso puede depender la salvación de la humanidad entera (...) A mí modo de ver, si por los motivos que fuesen los descubrimientos de Kepler y Newton hubieran podido darse a conocer solo el sacrificio de una persona, o de una docena o de un centenar de personas o de cuantas usted quiera que impidiesen tales descubrimientos $\mathrm{u}$ obstruyen la vía que conduce a ellos, Newton tendrá el derecho, más aun, la obligación de... eliminar a esa docena o a ese centenar de personas para dar a conocer sus descubrimientos a la humanidad entera. Pero de ahí no se deduce que Newton tuviera el derecho de matar a diestro y siniestro o robar a diario en el mercado. (Dostoievski, 1982, pág. 345)

Según Raskólnikov, hay personas que por sus características especiales no solo les está permitido asesinar a personas a las que considera como abyectas o piojos, sino que hacerlo es casi una obligación del Übermensch, estarían aquí los valores del guerrero, de la bestia rubia germánica del que habla Nietzsche.
De acuerdo a Raskólnikov el hombre napoleón está extinto de toda responsabilidad porque tiene completa libertad, en efecto:

Para un hombre como Napoleón todo le estaba permitido -cañonea Tolón, organiza una matanza en París, olvida a su ejército en Egipto, sacrifica medio millón de hombres en Rusia-... a este hombre (Napoleón) después de muerto, se le erigen monumentos, estatuas, por lo tanto, todo está permitido... (Dostoievski, 1982, pág. 381)

Si hacemos una breve símil entre el hombre napoleónico del que habla Raskólnikov y el Übermensch (superhombre) de Nietzsche, ambos desafían la moral, son parte de una casta especial que desafía las convenciones morales, ambos están en lucha contra los valores morales como la compasión, la obediencia, el ascetismo, entre otros. Ambos son nihilistas y exponen sólidamente sus argumentos. Veamos, si en Raskólnikov el nihilismo se representa como el hombre que está por encima de todos, que todo le es permitido, y que además es poseedor de una moral superior y por ende podría realizar, cometer, perpetrar cualquier acto, incluso el asesinato sin castigo y perjuicio moral; el nihilismo de Nietzsche es la desvalorización de los valores supremos, esto es, los valores pierden su sentido, no existen verdades absolutas, todo es interpretación, por ende todo se puede cambiar.

Entonces surge la interrogante ¿Es Raskólnikov un superhombre como él mismo piensa? Su pretensión de ser un superhombre o un hombre napoleónico estarían lejos de convertirse en realidad, el punto de quiebre es el remordimiento que siente por el crimen que cometió, su conciencia no lo deja en paz, así enferma súbitamente, terriblemente, el desasosiego embarga todo su ser hasta caer enfermo. Se siente derrotado, descubre que al asesinar a la llamada vieja usurera se había asesinado así mismo, vislumbra que cayó a lo más bajo, incluso más que todo personaje que en el libro se habla, más bajo que Sonia (prostituta), más bajo que Marmeladov (alcohólico) y más bajo que la propia usurera.

Un rasgo interesantísimo en la producción literaria de Dostoievski es la concepción del cristianismo ortodoxo, esto es, la expiación de los pecados se da en este mundo y no en otro lugar (luego de la muerte) como sugiere el cristianismo católico. En Crimen y castigo y específicamente en Raskólnikov se ve representado este credo, veamos, abatido el joven Raskólnikov se da cuenta que no es un superhombre 
y motivado por los consejos de Sonia confiesa su crimen, así es enviado a Siberia a cumplir su condena, ahí descubre que el hombre no está libre de hacer lo que quiera, que no todo le está permitido, que se rige por la moral y debe pagar su pena mediante el sufrimiento para alcanzar la redención, así trae a colación el pasaje bíblico de la resurrección de Lázaro que la propia Sonia leyera a Raskólnikov: soy la resurrección y la vida, quien crea en mí, no morirá para siempre. El desenlace del libro es la representación del pensamiento de Dostoievski, esto es, la redención a partir del sufrimiento o la penitencia (pena en Siberia).

\section{CONCLUSIONES}

De acuerdo a nuestras bases teóricas, concebimos al nihilismo como la transvaloración o trasmutación de los valores morales, específicamente de la moral judeocristiana, es decir, ascetismo, perdón, sacrificio. Sería la resultante del pensamiento nietzscheano que Dios ha muerto. No hay nada absoluto y, como tal, todo está permitido, que se posee una absoluta e ilimitada libertad. Se sugiere así, que los valores antes mencionados han perdido su significación a causa de sus propios feligreses. Propone, por tanto, otros valores, estos son la del Übermensch o del superhombre.

El nihilismo de Raskólnikov no solo está presente en el artículo que escribió, el que se titula: Acerca del delito, también está en los soliloquios que sostiene antes de cometer el crimen donde expone que existen dos tipos de hombres, estos son el hombre normal sujeto a la moral establecida y el superhombre o hombre napoleónico libre de toda moral y por tanto capaz de hacer todo sin ningún perjuicio, además de la trasgresión moral cristiana de no matar.

Raskólnikov fracasa en su intento por demostrarse que es un nihilista (experimenta el remordimiento) descubre que no es un superhombre y por tanto que no puede estar por encima de la condición humana, la retórica nihilista presente en Acerca del delito pierde toda significancia en este punto por la vulnerabilidad que experimenta (cae enfermo).

El nihilismo de Raskólnikov no permanece a lo largo de la novela, tiene un final, encuentra el ocaso luego de cometer el crimen, momento en el que descubre que no es un superhombre, que está regido por la moral y que tiene conciencia.

\section{REFERENCIAS}

Barros, B. (2011). Análisis y visualización del discurso en la obra crimen y castigo de F. M. Dostoievski. (Tesis doctoral, Universidad de Granada). Repositorio Institucional https://digibug.ugr.es/handle/10481/20265

Benn, G. (1999). El yo moderno y otros ensayos. Valencia, España: Pre-Textos.

Bravo, J. M. (1987). “Introducción” En los hermanos Karamazov. Madrid, España: Cátedra.

Dostoievski, F. (1982). Obras completas. Madrid, España: Aguilar.

Dostoievski, F. (2004). Diario de un escritor y otros escritos. Buenas Aires, Argentina: Tauro.

Feinmann, J. [Filosofía aquí y ahora]. (21 de marzo de 2016). Nietzsche: Dios ha muerto Capítulo 12 - Primera temporada. $\mathrm{R}$ e c u p e r a d o d e : https://www.youtube.com/watch?v=U8pyri5 $\mathrm{kjOE}$

Fink, Eugen. (1981). La filosofía de Nietzsche. Madrid, España: Alianza Universidad.

Frank, J. (1997). Dostoíevski, Los años milagrosos 1865-1871. México: FCE.

Maureira, M. (2010). Nihilismo del Idealismo. Jacobi frente a Fichte. Revista de Estudios sobre Fichte [Online]. Recuperado de: http://journals.openedition.org/ref/328

Nietzsche, F. (2008). Fragmentos póstumos. Vol. 4. Trad. De Juan Luis Vernal y Joan B. Llenares. Madrid, España: Tecnos.

Nietzsche, F. (1992). La ciencia jovial. La Gaya Scienza. Trad. José Jara. Monte. Venezuela: Ávila Editores.

Nietzsche, F. (1985). Así habló Zaratustra. Trad. José Jara. Monte. Madrid, España: Alianza Editorial.

Nietzsche, F. (1972). Más allá del bien y del mal. Trad. Andrés Sánchez Pascual. Madrid, España: Alianza Editorial.

Nietzsche, F. (1973). El Anticristo. Trad. Andrés Sánchez Pascual. Madrid, España: Alianza Editorial.

Nietzsche, F. (1972). Genealogía de la moral. Trad. Andrés Sánchez Pascual. Madrid, España: Alianza Editorial.

Nietzsche, F. (1981). La Voluntad de Poder. Trad. de Aníbal Froufe. Madrid, España: Biblioteca Edaf.

Sánchez, A. J. (2014). Nietzsche y Dostoievski ante el nihilismo. Un estudio comparativo. (Manuscrito presentado para publicación). 
Universidad Nacional Autónoma de México. Sánchez Meca, D. (2016). [SEMINARIO NIETZSCHE COMPLUTENSE SNC]. (01 de octubre de 2016). Diego Sánchez Meca: "Dioniso contra el Crucificado: la inversión de todos los valores". Recuperado de https://www.youtube.com/watch?v=BxG1dE PTHUE

Vilas Boas, J. S. (2016). Niilismo, fanatismo e terror: uma leitura do fundamentalismo a partir de
Friedrich Nietzsche (tesis doctoral). Universidad Estatal de Campinas, Brasil. Re pos it orio Institucion a 1: http://bdtd.ibict.br/vufind/Record/UFT 47c6 bbe29a1695f7bb9b06448eca165a

Turgenev. (1987). Padres e hijos. Madrid, España: Alianza Editorial. 